\title{
USE OF WOUND PROTECTOR FOR PREVENTION OF SURGICAL SITE INFECTION IN LAPAROSCOPIC CHOLECYSTECTOMY
}

\author{
Professor Vadim V. Kryzhevskii ${ }^{1}$, Associate Professor Mykola A. Mendel ${ }^{1,2}$, \\ Anna P. Brodskaya ${ }^{1}$, Yulia V. Pavlovych ${ }^{1,2}$ \\ ${ }^{1}$ Shupyk National Medical Academy of Postgraduate Education, General and Emergency Surgery \\ Department, Kyiv, Ukraine \\ ${ }^{2}$ Medical center «Oberig», Kyiv, Ukraine
}

DOI: https://doi.org/10.31435/rsglobal_ws/31032020/6974

\section{ARTICLE INFO}

Received: 18 January 2020

Accepted: 14 March 2020

Published: 31 March 2020

\section{KEYWORDS}

laparoscopic cholecystectomy, surgical site infection,

wound protector.

\begin{abstract}
The work is based on the experience of 759 cholecystectomies performed in 2015-2018. Patients with a 3-4 grades of microbial contamination of wounds were divided into two groups: the first, with removal of the gallbladder traditionally with specimen retrieval container and the second, where proposed method of combined use of container and wound protector was used -19 patients.

Surgical site infection in laparoscopic cholecystectomy was detected in $5.40 \%$ (41 patients out of 759). During surgical interventions related to the second grade of microbial contamination (clean-contaminated), the frequency of SSI was $2.50 \%$, to the third grade (contaminated) $11.76 \%$, and to the fourth grade (dirty) $-34.92 \%$. Using the proposed method for the simultaneous use of the retrieval container and the double-ring wound protector in the second and third grades of wounds in LC allowed to reduce the frequency of SSI from $37.70 \%$ to $5.26 \%$.
\end{abstract}

Citation: V. Kryzhevskii, Mykola A. Mendel, Anna P. Brodskaya, Yulia V. Pavlovych. (2020) Use of Wound Protector for Prevention of Surgical Site Infection in Laparoscopic Cholecystectomy. World Science. 3(55), Vol.2. doi: 10.31435/rsglobal_ws/31032020/6974

Copyright: (C) 2020 V. Kryzhevskii, Mykola A. Mendel, Anna P. Brodskaya, Yulia V. Pavlovych. This is an open-access article distributed under the terms of the Creative Commons Attribution License (CC BY). The use, distribution or reproduction in other forums is permitted, provided the original author(s) or licensor are credited and that the original publication in this journal is cited, in accordance with accepted academic practice. No use, distribution or reproduction is permitted which does not comply with these terms.

Laparoscopic cholecystectomy (LC) is one of the most frequently performed surgical operations in the world. However, surgical site infections (SSI) after this operation have rate from 2.4 to $9.6 \%$, regardless of the preventive measures taken, and give a significant burden on the healthcare system $[1,2,3]$. That is why the problem of the prevention of SSI after LC remains actual and studies aimed at its solution are practically important for modern surgery.

One of the main ways to prevent SSI is prevention wound bacterial contamination. Usual accepted measures, such as following aseptic rules, skin preparation, surgical masks, antimicrobial prophylaxis, etc., are mostly focus on preventing outside wound contamination. These measures work efficiently in "clean" operations (the first grade of microbial contamination) $[4,5]$, where wound contamination is possible only from the outside skin, instruments and air, and not from the abdominal cavity. However, even elective LC belongs at least to the second grade of wounds ("cleancontaminated"). Therefore, for wounds of the second grade, additional measures are used: closing wound edges, preventing contact of bile with the wound during gallbladder (GB) removing from abdominal cavity, introducing cystic duct into the trocar or extracting specimen in the container $[1,2,3]$.

The problem is the "contaminated" wounds, which are related to microbial contamination of the third grade (in cases of abdominal cavity contamination: intraoperative perforation of the gallbladder wall, GB necrosis without peritonitis) $[4,6]$. In these cases, simple placement of the GB in 
the specimen retrieval container does not isolate wound edges because of the container in the abdominal cavity is also contaminated outside. When container removed from the abdominal cavity through a trocar wound contamination of the wound from the outer walls of the container is possible.

In "dirty or infected" operations (4th grade of microbial contamination), for example purulent inflammation of GB, empyema with intraoperative puncture of GB, perivesical abscesses, peritonitis, most often the wound in the abdominal wall is not infected immediately after entering the abdominal cavity, as the infection is most often localized in the right hypochondrium. The situation is much similar to the operations of the third grade, since placing the container in a contaminated environment also causes its contamination from the outside.

Protection of wound edges from contamination during specimen extraction can be achieved with double-ring wound protectors, which consist of two elastic rings that are interconnected by a hermetic plastic membrane. One of these rings is inserted through the wound into the abdominal cavity, the other remains outside, they stretch the membrane, which protects the edges of the wound.

The disadvantage of this method is that when the GB with damaged wall is removed without container, there can be spillage of gallstones and pathological content in the abdominal cavity, which leads to intra-abdominal infection complications. That's why we decided to combine these two techniques and assess effectiveness of proposed method.

Objective. To evaluate the effectiveness of the developed method for the prevention of SSI after LC using at the same time a specimen retrieval container and double-ring wound protector.

Materials and methods. The work is based on the experience of 759 cholecystectomies performed in 2015-2018 at the clinical bases of the Department of General and Emergency Surgery of the National Medical Academy of Postgraduate Education named after P.L. Shupik (Kiev City Clinical Hospital No. 6 and Oberig Medical Center). 381 patients had acute cholecystitis and 378 had chronic calculous cholecystitis.

Operations of the 4th grade of microbial contamination $[4,5]$ were performed in 63 patients. 13 patients had acute gangrenous-perforated cholecystitis, 27 had acute gangrenous cholecystitis with local peritonitis and perivesical abscesses, and 23 had empyema of the gallbladder.

Cases with intraoperative perforation of the gallbladder with leakage of bile into the abdominal cavity or gallstones spillage were assigned to surgical wounds of the 3rd grade of microbial contamination (Fig. 1). Estimating the true frequency of gallbladder perforation is quite difficult, because not all surgeons noted this in the operation reports, however, when analyzing the last 80 consecutive operations, 17 (21.25\%) perforations were detected.

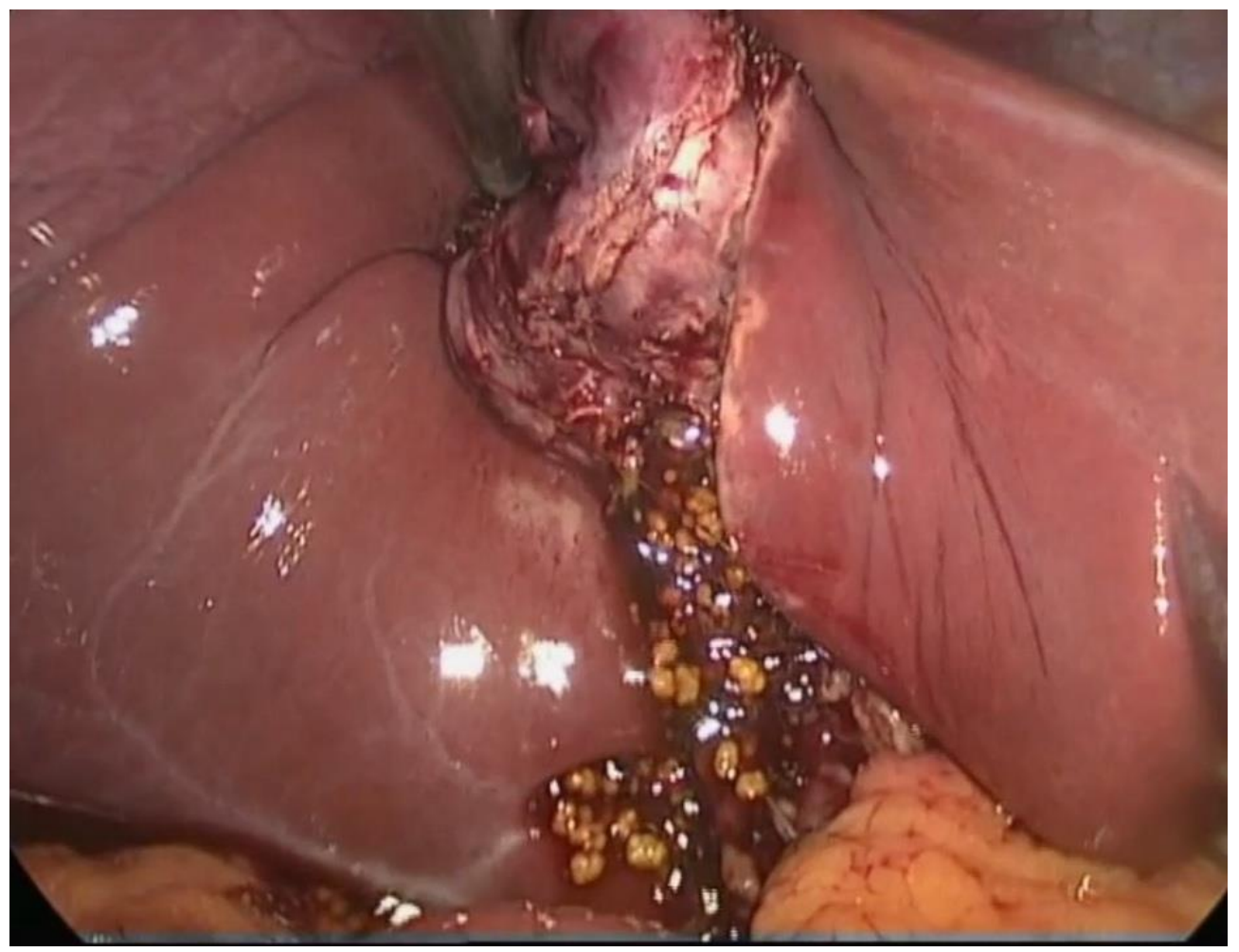

Fig. 1. Gallstones spillage from accidental gallbladder perforation 
It was impossible to reliably estimate true frequency of intraoperative perforations during previous operations. Therefore, all other operations (679) were assigned to the second grade of microbial wound contamination. 21 patients underwent conversion to laparotomy (subcostal -7 and midline -14). In patients with 4th grade wounds conversions were performed in 8 cases.

All patients underwent preoperative antibiotic prophylaxis with cefuroxime 1.5 grams IV (166 patients) or ceftriaxone 2 grams IV (593 patients). When removing the gallbladder in case of chronic cholecystitis and in patients with polyp specimen retrieval container was not used; in acute cholecystitis or intraoperative perforation of the gallbladder, sterile disposable containers were used. After specimen extraction a gauze wipe with $10 \%$ povidone-iodine solution was applied to the trocar wound for 1 minute.

Wound assessment was performed during sutures removing on 7-9 postoperative days at an outpatient visit of the patient or when the patients were in the hospital.

When a wound infection occurred, a bacteriological study was performed, the edges of the wound were opened and treatment was performed until the wound healed or secondary sutures were applied. In most cases of wound infection in trocar wounds systemic antibiotic therapy was not administered. In patients with SSI after conversion broad-spectrum antibiotics were prescribed (protected aminopenicillins, fluoroquinolones).

Patients with a 3-4 grades of microbial contamination of wounds were divided into two groups: the first, with removal of the gallbladder traditionally with specimen retrieval container and the second, where proposed method of combined use of container and wound protector was used (Patent of Ukraine for utility model No. 136045) [7].

The technique was performed in following way: after laparoscopic cholecystetomy in patients with 3-4 wound grades, a sterile plastic container was inserted into the abdominal cavity through a trocar and removed GB was placed in specimen retrieval bag. The trocar wound, through which it was planned to remove GB from abdominal cavity, was enlarged according to the size of GB with stones. The trocar was removed and a double-ring wound protector was introduced into the wound. A clamp was introduced through the protector, a container was catch and removed from the abdominal cavity by traction (Fig. 2). We use wound protectors Surgisleeve (Medtronic, USA).

The second group included 19 patients, 10 with a 3 rd grade of wounds and 9 with a $4^{\text {th }}$ grade.

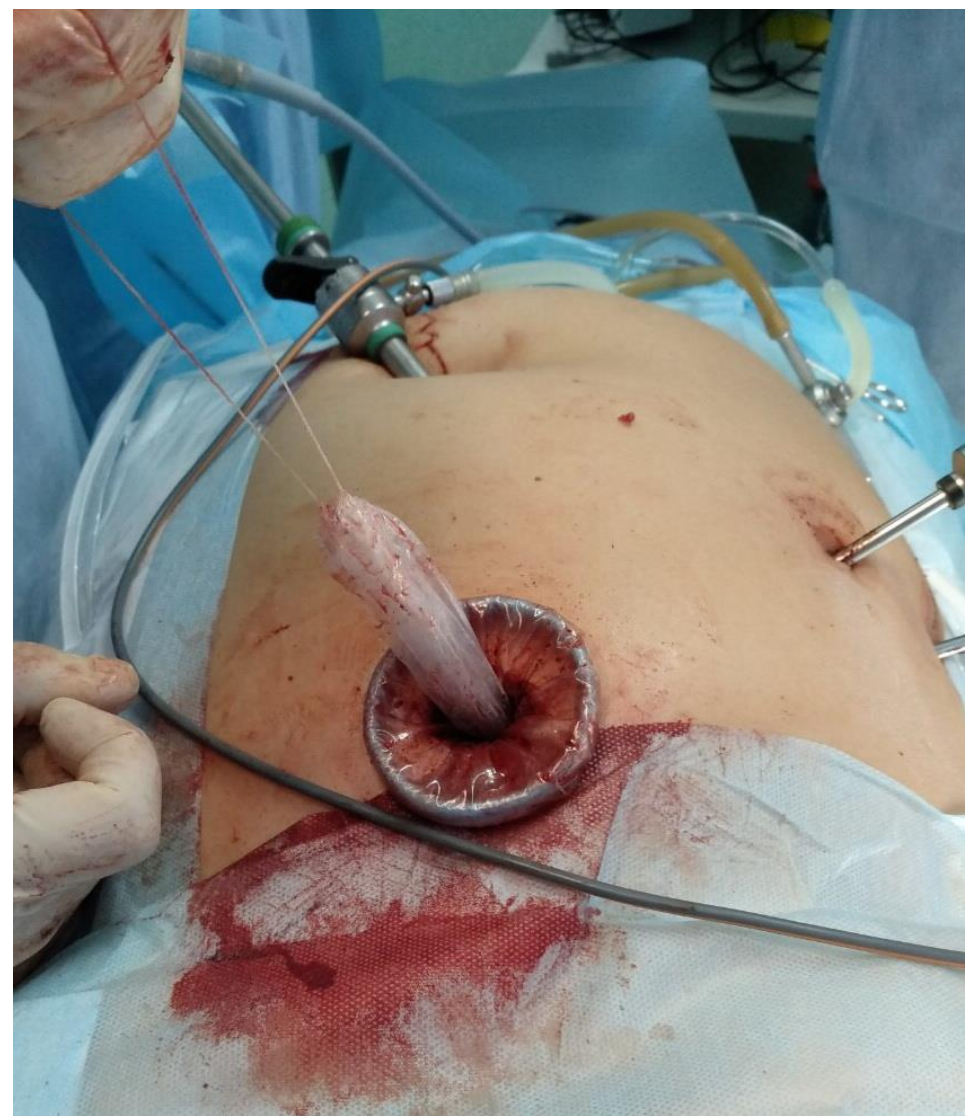

Fig. 2. The method of combined use of the extraction container and double-ring wound protector (Ukraine utility model patent No. 136045) 
Results. An analysis of the results is presented in table 1.

Superficial SSI detected in 41 patients $(5.40 \%)$. During bacteriological studies microbial associations were isolated in $14.63 \%$ (6 patients), and the remaining 35 patients $(85.37 \%$ ) had monocultures. The following microorganisms were isolated: most often E. coli (21 patients), S. aureus, S. epidermidis, Proteus vulgaris, Pseudomonas aeruginosa, Acinetobacter, Enterobacter.

In patients with clean-contaminated wounds (Grade 2) frequency of SSI was 2.50\% (17 patients). However, in this group 14 patient underwent conversions and 4 of them (28.57\%) developed SSI, while the frequency of SSI in patients with trocar wounds was $1.95 \%$ (13 patients).

From 17 patients with intraoperative perforation of GB (3rd grade of surgical wounds) SSI developed in $2(11.76 \%)$, both of these patients were in the group without use of a wound protector. In one patient, the operation was also accompanied by a massive spillage of gallstones into the abdominal cavity (Figure 1). Frequency of SSI in this grade of wounds without the use of protector was $28.57 \%$ while when using a protector wound complications were not observed.

In patients with infected wounds (grade 4 wounds) the frequency of SSI was 34.92\% (22 patients). Conversion was performed in 8 patients of this group and wound complications occurred in $4(50 \%)$. In patients with trocar wounds the frequency of SSI was 28.57 percent (17 patients $(36.95 \%)$ in the first group and 1 patient $(11.11 \%)$ in the second group.

The greatest risk of wound infection after LC was in patients with conversion - 38.09\% (8 out of 21 patients).

Using the proposed method for the simultaneous use of the retrieval container and the doublering wound protector in the second and third grades of wounds in LC allowed to reduce the frequency of SSI from $37.70 \%$ to $5.26 \%$.

Table 1. Rate of SSI in laparoscopic cholecystectomy

\begin{tabular}{|c|c|c|c|c|c|c|c|c|c|}
\hline \multirow{2}{*}{$\begin{array}{l}\text { Wound } \\
\text { grade }\end{array}$} & \multicolumn{3}{|c|}{ Group 1} & \multicolumn{3}{|c|}{ Group 2} & \multicolumn{3}{|c|}{ Total } \\
\hline & Patients & SSI & $\%$ & Patients & SSI & $\%$ & Patients & SSI & $\%$ \\
\hline \multicolumn{10}{|c|}{ Only 3-4 } \\
\hline 3 & 7 & 2 & 28,57 & 10 & 0 & 0 & 17 & 2 & 11,76 \\
\hline 4 & 54 & 21 & 38,89 & 9 & 1 & 11,11 & 63 & 22 & 34,92 \\
\hline Total & 61 & 23 & 37,70 & 19 & 1 & 5,26 & 80 & 24 & 30,00 \\
\hline \multicolumn{10}{|c|}{ Without conversion } \\
\hline 2 & 665 & 13 & 1,95 & 0 & - & - & 665 & 13 & 1,95 \\
\hline 3 & 7 & 2 & 28,57 & 10 & 0 & 0 & 17 & 2 & 11,76 \\
\hline 4 & 46 & 17 & 36,96 & 9 & 1 & 11,11 & 63 & 18 & 28,57 \\
\hline Total & 718 & 32 & 4,46 & 19 & 1 & 5,26 & 745 & 33 & 4,43 \\
\hline
\end{tabular}

Discussion. Although surgeons have progressively paid more attention to the control of operative wound contamination during surgical procedures, incisional surgical site infection (SSI) is still a frequent postoperative adverse event jeopardizing patient safety and increasing health care costs. [4].

Despite the fact that the introduction of laparoscopy has reduced the likelihood of SSI, the weak point is a possible wound contamination while removing gallbladder from abdominal cavity.

Techniques for removing an infected organ from the abdominal cavity during laparoscopic surgery in a plastic container bag through a normal or enlarged trocar wound are known. In these techniques gallbladder is placed in a plastic container bag and container is removed through the wound $[1,2,3]$. There was no statistically significant difference in SSI rate between use of container or removing gallbladder without container in these studies. But in all these studies rate of SSI remains high. Possibly it is because there was no division of cholecystectomies in grades of wound contamination. In cases of elective operation probability of infection is very low and use of container doesn't change situation vs. no container at all. Situation differs in cases of contaminated or infected wounds. The disadvantage of container use is that there is possibility of wound edges contamination from the walls of the container which was in contact with the infectious contents in the abdominal cavity not only from the inside but also from the outside, which could lead to the development of wound infection in the postoperative period.

At the same time, there are ways to protect the edges of the wound using double-ring wound protectors which consist of two elastic rings that are interconnected by a hermetic plastic membrane. One of these rings is inserted through the wound into the abdominal cavity and other remains outside. 
Rings stretch the membrane that protects the edges of the wound. The disadvantage of these methods is that when the infected organ is removed in case of damage to its wall, pathological contents may enter the abdominal cavity, which leads to the development of infectious intra-abdominal complications. Perhaps this explains the results of a similar number of SSI when using containers to remove gallbladder and to remove it without the container $[1,2,3]$.

We set the task of creating such a method for the prevention of infection of trocar wounds during laparoscopic operations, which, due to the exclusion of contact between the walls of the container and the walls of the wound would ensure the prevention of wound contamination and development of SSI [7]. This technique was tested in the treatment of 19 patients. It was possible to reduce the frequency of SSI in patients with second and third grades of wounds after LC from $37.70 \%$ to $5.26 \%$.

An important result of the study was also the high frequency of SSI during conversion to laparotomy $(38.09 \%)$. We explain this by the fact that during a conversion performed under conditions of intraoperative stress, with the development of complications, the principles of protecting the edges of wounds are often violated, and the time and invasiveness of the operation also increase.

In a previous study of the frequency of complications of cholecystectomy published in 2014 from our clinic the frequency of SSI was $8.4 \%$. After this study we improve organizational and technical methods for the prevention of wound complications [8]. This approach has led to a decrease in the SSI rate to $5.40 \%$, which, in general, is consistent with current literature data $[1,2,3,4]$. Despite the small group studied, the proposed method for the prevention of SSI is promising and can be recommended for clinical use and further scientific study in randomized trials.

Conclusions. Surgical site infection in laparoscopic cholecystectomy was detected in $5.40 \%$ (41 patients out of 759).

During surgical interventions related to the second grade of microbial contamination (cleancontaminated), the frequency of SSI was $2.50 \%$, to the third grade (contaminated) $-11.76 \%$, and to the fourth grade (dirty) $-34.92 \%$.

Conversion with LC is accompanied by a high rate of wound infection $-38.09 \%$.

Using the proposed method for the simultaneous use of the retrieval container and the doublering wound protector in the second and third grades of wounds in LC allowed to reduce the frequency of SSI from $37.70 \%$ to $5.26 \%$.

\section{REFERENCES}

1. Comajuncosas J, Hermoso J, Jimeno J, Gris P, Orbeal R, Cruz A, Parés D. Effect of bag extraction to prevent wound infection on umbilical port site wound on elective laparoscopic cholecystectomy: a prospective randomised clinical trial. Surg Endosc. 2017 Jan;31(1):249-254. doi: 10.1007/s00464-016-4965-z.

2. La Regina D, Mongelli F, Cafarotti S, Saporito A, Ceppi M, Di Giuseppe M, Ferrario di Tor Vajana A. Use of retrieval bag in the prevention of wound infection in elective laparoscopic cholecystectomy: is it evidence-based? A meta-analysis. BMC Surg. 2018 Nov 19;18(1):102. doi: 10.1186/s12893-018-0442-z.

3. Majid MH, Meshkat B, Kohar H, El Masry S. Specimen retrieval during elective laparoscopic cholecystectomy: is it safe not to use a retrieval bag? BMC Surg. 2016 Sep 19;16(1):64. doi: 10.1186/s12893-016-0181-y.

4. WHO. Global guidelines on the prevention of surgical site infection, 2016. - http://www.who.int/gpsc/ssiguidelines/en/\#

5. Profilaktika infekcij oblasti hirurgicheskogo vmeshatel'stva. Klinicheskie rekomendacii. N. Novgorod: Izdvo «Remedium Privolzh'e», 2018. - 72 p.

6. Zinn JL. Surgical wound classification: communication is needed for accuracy. AORN J. 2012 Feb;95(2):274-8. doi: 10.1016/j.aorn.2011.10.013.

7. Patent na korysnu model 136045 Ukrainy, MPK A61B17/00 A61B1/313. Sposib profilaktyky infikuvannia troakarnoi rany pry laparoskopichnykh operatsiiakh: Pat. 136045 Ukrainy, MPK A61B17/00 A61B1/313/ Kryzhevskyi V.V., Mendel M.A., Pavlovych Yu.V., Brodska A.P. - №u201904147; Zaiavl.18.04.2019; Opubl. 25.07.2019; Biul. №14

8. Biliaieva O. O., Korzhyk N. P., Myronov O. M., Yemets V. V., Miroshnichenko A. P., Biliaiev V. V. Zhovchnokamiana khvoroba: uskladnennia ta reabilitatsiia. Klinichna khirurhiia. 2014; 11:32-43. 